\title{
Modification of $\mathrm{N}$-Terminal Amino Acids of Fungal Benzoate Hydroxylase (CYP53A15) for the Production of $p$-Hydroxybenzoate and Optimization of Bioproduction Conditions in Escherichia colis ${ }^{5}$
}

\author{
Shun Tamaki ${ }^{1}$, Mitsuhiko Yagi ${ }^{1}$, Yuki Nishihata ${ }^{1}$, Hideki Yamaji ${ }^{2}$, Yasushi Shigeri ${ }^{3}$, Tomohide Uno ${ }^{4}$, and \\ Hiromasa Imaishi ${ }^{1 *}$ \\ ${ }^{1}$ Division of Signal Responses, Biosignal Research Center, Kobe University, Nada, Kobe 657-8501, Japan \\ ${ }^{2}$ Department of Chemical Science and Engineering, Graduate School of Engineering, Kobe University, Nada, Kobe 657-8501, Japan \\ ${ }^{3}$ Health Research Institute, National Institute of Advanced Industrial Science and Technology (AIST), Takamatsu, Kagawa 761-0395, Japan \\ ${ }^{4}$ Laboratory of Biochemistry, Graduate School of Agricultural Science, Kobe University, Nada, Kobe 657-8501, Japan
}

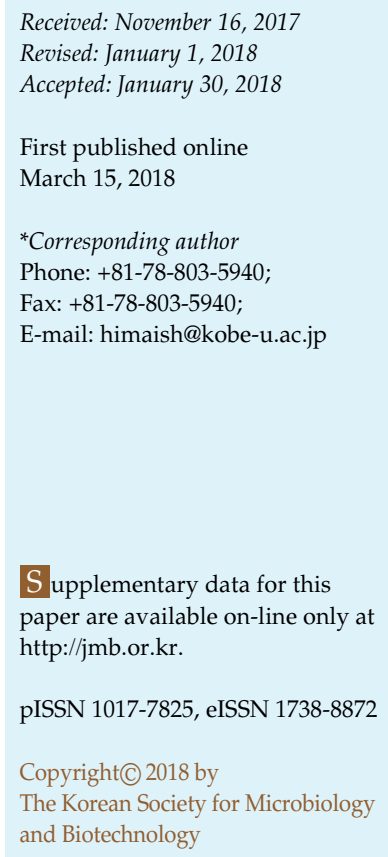

\begin{abstract}
The aromatic compound $p$-hydroxybenzoate (PHBA) is an important material with multiple applications, including as a building block of liquid crystal polymers in chemical industries. The cytochrome P450 (CYP) enzymes are beneficial monooxygenases for the synthesis of chemicals, and CYP53A15 from fungus Cochliobolus lunatus is capable of executing the hydroxylation from benzoate to PHBA. Here, we constructed a system for the bioconversion of benzoate to PHBA in Escherichia coli cells coexpressing CYP53A15 and human NADPH-P450 oxidoreductase $(C P R)$ genes as a redox partner. For suitable coexpression of CYP53A15 and $C P R$, we originally constructed five plasmids in which we replaced the N-terminal transmembrane region of CYP53A15 with a portion of the $\mathrm{N}$-terminus of various mammalian P450s. PHBA productivity was the greatest when CYP53A15 expression was induced at $20^{\circ} \mathrm{C}$ in $2 \times Y$ T medium in host $E$. coli strain $\triangle g c v R$ transformed with an N-terminal transmembrane region of rabbit CYP2C3. By optimizing each reaction condition (reaction temperature, substrate concentration, reaction time, and E. coli cell concentration), we achieved $90 \%$ wholecell conversion of benzoate. Our data demonstrate that the described novel E. coli bioconversion system is a more efficient tool for PHBA production from benzoate than the previously described yeast system.
\end{abstract}

Keywords: $p$-Hydroxybenzoate, cytochrome P450, CYP53A15, bioconversion

\section{Introduction}

$p$-Hydroxybenzoate (PHBA) is an important building block of liquid crystal polymers (LCPs) in the chemical polymer industry [1]. LCPs are special chemical products that are used in electronics and fiber industries. The demand for LCPs is increasing, especially in the electronics industry. Moreover, PHBA is the base material of preservatives in the cosmetic and pharmaceutical industries. Although organic synthetic chemistry can synthesize PHBA, it is derived from non-renewable petroleum resources and its synthesis is energy intensive. Here, we attempted to produce PHBA from benzoate in recombinant Escherichia coli expressing fungal cytochrome P450 (CYP53A15).

P450 is a member of the ubiquitous heme-thiolate monooxygenase family, which is widely distributed in all biological kingdoms, from prokaryotes to eukaryotes [2]. P450s play an important role in the oxidation of endogenous and exogenous compounds, including xenobiotics and secondary metabolites. During the catalytic cycle, these enzymes require reducing electrons, which are normally provided by NADPH catalyzed by cytochrome P450 
reductase (CPR) [3]. Because of their reaction selectivity and acceptance of a wide range of substrates, P450s have long been considered attractive enzymes for the synthesis of chemicals and pharmaceuticals $[4,5]$.

Multiple members of the CYP53 family of cytochrome P450 monooxygenases have $p$-hydroxylase activity against benzoate. CYP53 enzymes are essential for plant pathogenic fungi, as they play crucial roles in detoxification and the degradation of plant defensive phenolic compounds (e.g., benzoate) [6,7]. Benzoate is hydroxylated to PHBA by CYP53 catalysis and is then metabolized through the $\beta$ ketoadipate pathway to produce intermediates that enter the TCA cycle and are utilized as carbon sources [8,9]. The CYP53A15 enzyme is produced by the filamentous fungus Cochliobolus lunatus, an opportunistic plant and human pathogen. The enzymatic properties of purified recombinant CYP53A15 (expressed by E. coli) have been characterized. CYP53A15 can hydroxylate benzoate to either PHBA or 3,4dihydroxybenzoate, depending on which endogenous CPR it is combined with. Moreover, a mutant $C$. lunatus strain deficient in CYP53A15 has been shown to be more susceptible to benzoate than the wild-type strain is, demonstrating an essential role of this enzyme in detoxification of a plant defensive compound [6, 7].

Recently, Noda et al. [10] have shown that endoglucanasesecreting Streptomyces maritimus can produce benzoate from cellulose, thereby demonstrating that it is possible to produce CYP53A15 substrates from plant biomass. Moreover, PHBA has been produced in a yeast strain coexpressing CYP53A19 and CPR from Fusarium oxysporum and glucose dehydrogenase from Bacillus subtilis, thereby enhancing the NADPH regeneration system. However, this approach is hindered by a complex culture procedure and a maximum PHBA yield of $61 \%$ [11].

Here, we attempted to develop a bioconversion system of benzoate to PHBA by using E. coli expressing CYP53A15 and human $C P R$. Although, in most cases, the heterologous and excessive expression of eukaryotic membrane-bound P450s in E. coli is not easy, we have originally constructed a series of expression plasmids for membrane-bound P450s in E. coli [12], as described in detail below. Therefore, we first attempted to optimize the $\mathrm{N}$-terminal amino acid sequence of CYP53A15 for heterologous expression in E. coli using our P450 expression plasmids. Second, to maximize the gene expression and enzyme activity of CYP53A15, we optimized the choice of E. coli host, culture conditions (temperature and medium), and reaction conditions (reaction temperature, substrate concentration, reaction duration, and E. coli density).

\section{Materials and Methods}

\begin{abstract}
Materials
PHBA, ampicillin, 5-aminolevulinic acid hydrochloride, isopropyl $\beta$-D-thiogalactopyranoside (IPTG), and methanol were purchased from Nacalai Tesque (Japan). Benzoate was purchased from Wako Pure Chemical Industries (Japan). 8-Methoxypsoralen (8-MOP) was purchased from Extrasynthese (France). The other chemicals were commercially available.
\end{abstract}

\section{Construction of CYP53A15 Expression Plasmids}

CYP53A15 cDNA with two nucleotide substitutions (G105C and C107G) and six additional nucleotides was artificially synthesized by GeneArt Gene Synthesis (Thermo Fisher Scientific, USA), and obtained as a pMK-RQ-CYP53A15 plasmid; these nucleotide modifications add SmaI (CCCGGG) and SalI (GTCGAC) recognition sites (Fig. 1A). The pMK-RQ-CYP53A15 plasmid was digested with SmaI and SalI and ligated into five modified PCWR vectors for coexpression of P450 and CPR (Fig. 1B). These five modified pCWR vectors each contain one of various DNA sequences encoding N-terminal peptides of mammalian P450s at the start codon, as follows: pCWRm1A2N (MALLLAVFLFCLVFWMVR ASRTQVPKGLKNPPG); pCWRrab2C3N (MAKKTSSKGKLPPG); pCWRr2C11N (MARQSFGRGKLPPG); pCWRm2C29N (MARQSS GRGKLPPG); and pCWRh2E1N (MARQVHSSWNLPPG) (Fig. 1C). The resulting plasmids were introduced into E. coli strains JM109 and BL21(DE3) (Takara, Japan), and BW25113, $\Delta g c v R, \Delta c p x A$, and $\Delta g l n L$, which were obtained from the National BioResource ProjectE. coli (NBRP-E. coli) at the National Institute of Genetics (Japan).

\section{Expression of CYP53A15 in E. coli}

E. coli strains JM109, BL21(DE3), BW25113, $\Delta g c v R, \Delta c p x A$, and $\Delta g l n L$ transformed with each pCWR-CYP53A15 plasmid were grown in $3 \mathrm{ml}$ of LB medium containing ampicillin $(50 \mu \mathrm{g} / \mathrm{ml})$. After overnight culture at $37^{\circ} \mathrm{C}$, the cultures were transferred to $100 \mathrm{ml}$ of Terrific Broth (TB; $1.2 \%$ tryptone, $2.4 \%$ yeast extract, $0.4 \%$ glycerol, $100 \mathrm{mM}$ potassium phosphate buffer, $\mathrm{pH} 7.4)$ ) with ampicillin $(50 \mu \mathrm{g} / \mathrm{ml})$ and grown to an $\mathrm{OD}_{600}$ of 0.5 . IPTG $(1 \mathrm{mM})$ and 5-aminolevulinic acid hydrochloride $(0.5 \mathrm{mM})$ were then added, and the cells were incubated at $25^{\circ} \mathrm{C}$ with shaking at $170 \mathrm{rpm}$ for $24 \mathrm{~h}$. Other growth media (LB, $2 \times Y \mathrm{~T}$ (1.6\% tryptone, $1 \%$ yeast extract, $0.5 \%$ sodium chloride), and Super Broth (SB; $3.2 \%$ tryptone, $2 \%$ yeast extract, $0.5 \%$ sodium chloride) ) and induction temperatures $\left(15^{\circ} \mathrm{C}, 20^{\circ} \mathrm{C}\right.$, and $\left.30^{\circ} \mathrm{C}\right)$ were also tested, as described below. Recombinant $E$. coli cells were harvested by centrifugation at $5,000 \times \mathrm{g}$ for $10 \mathrm{~min}$ at $4^{\circ} \mathrm{C}$ and resuspended in $10 \mathrm{ml}$ of $100 \mathrm{mM}$ potassium phosphate buffer ( $\mathrm{pH}$ 7.4) containing $1 \mathrm{mM}$ ethylenediaminetetraacetic acid (EDTA) and 20\% glycerol, and stored at $-80^{\circ} \mathrm{C}$ until later use.

\section{Determination of P450 Contents}

Reduced CO-difference spectra were measured in a Hitachi UV visible spectrophotometer (U-3300; Hitachi, Japan), as previously 
A

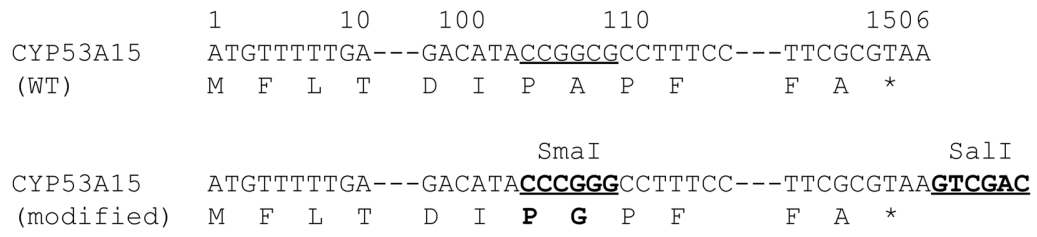

B

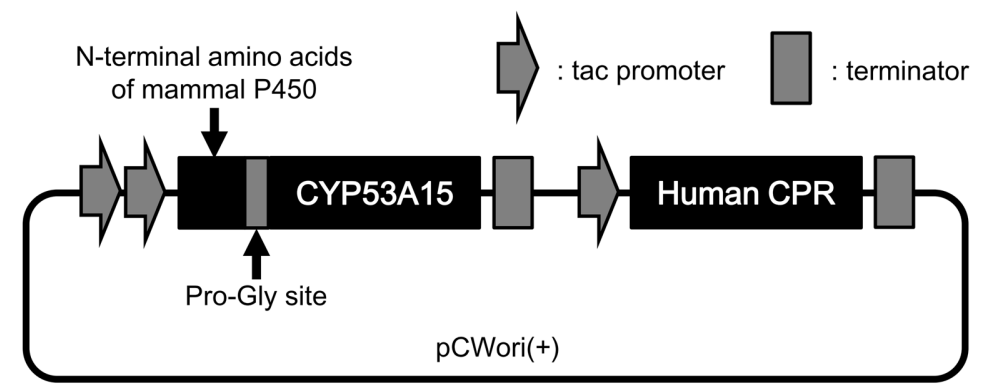

C

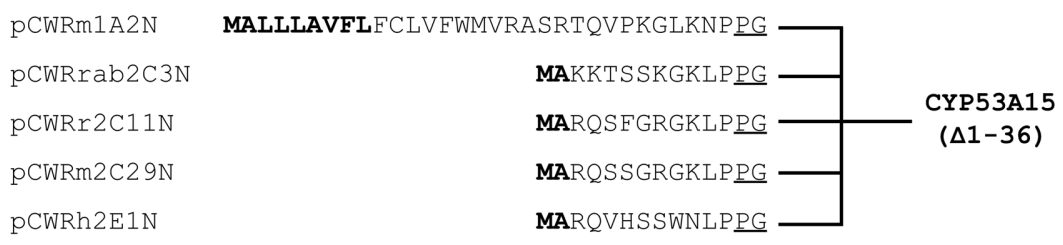

Fig. 1. Structure of the expression plasmid and modification of the N-terminal amino acids of CYP53A15.

(A) Wild-type (above) and mutation sites (below) in the CYP53A15 sequence. SmaI (corresponding to Pro-Gly site) and Sall recognition sites were introduced. (B) Schematic diagram of the structure of the expression plasmid used in this study. A fusion form of CYP53A15 (composed of partial N-terminal amino acids of mammalian P450, Pro-Gly site, and truncated CYP53A15) and human CPR were coexpressed in E. coli. (C) N-Terminal amino acid sequences of mammalian P450 encoded by each cassette plasmid. Amino acids in bold and underlined represent additional modification for P450 expression in E. coli cells and the Pro-Gly site, respectively. In our expression system, the bases encoding the initial 36 amino acids of CYP53A15, which correspond to the transmembrane region, were deleted. m1A2, mouse CYP1A2; rab2C3, rabbit CYP2C3; r2C11, rat CYP2C11; m2C29, mouse CYP29; and h2E1, human CYP2E1.

described [13]. The P450 hemoprotein contents in the E.coli suspensions were determined by using an extinction coefficient of $91.1 \mathrm{mM}^{-1} \mathrm{~cm}^{-1}[14]$.

\section{Bioconversion of Benzoate}

The benzoate to PHBA reaction was performed in $100 \mathrm{mM}$ potassium phosphate buffer ( $\mathrm{pH} 7.4$ ) containing 1 mM EDTA, 20\% glycerol, and $2 \mathrm{mM}$ benzoate unless otherwise stated. To start the reaction, $50 \mu \mathrm{l}$ of $E$. coli suspension was added to $1 \mathrm{ml}$ of the reaction mixture, which was then incubated at $30^{\circ} \mathrm{C}$ with shaking at $170 \mathrm{rpm}$ for $16 \mathrm{~h}$. Other benzoate concentrations, reaction temperatures, reaction times, and E. coli cell concentrations were also tested, as described below. The enzymatic reactions were stopped by the addition of $150 \mu \mathrm{l}$ of $2 \mathrm{~N} \mathrm{HCl}$ and $10 \mu \mathrm{l}$ of $10 \mathrm{mM} 8$ MOP as an internal standard. A $500-\mu \mathrm{l}$ aliquot of the mixture was added to the same volume of methanol. After thorough agitation, the mixture was centrifuged at $11,000 \times g$ to remove the cells and debris. The supernatant was filtered through a Millex-LH filter (Millipore, USA), before analysis by high-performance liquid chromatography (HPLC).

\section{HPLC Analysis}

A portion of the extract $(20 \mu \mathrm{l})$ was analyzed in an HPLC system (Hitachi) equipped with a TSKgel C18 column (ODS-80Ts, $150 \times$ $4.6 \mathrm{~mm}$; Tosoh, Japan). The mobile phases for HPLC were (A) $20 \mathrm{mM}$ phosphate buffer ( $\mathrm{pH} 2.5$ ) in $10 \%$ methanol, and (B) $20 \mathrm{mM}$ phosphate buffer ( $\mathrm{pH} 2.5$ ) in $90 \%$ methanol. The gradient solvent ratios of A:B were 50:50 for $0-8 \mathrm{~min}$ and $0: 100$ for $8-10$ $\mathrm{min}$. The flow rate was set to $1 \mathrm{ml} / \mathrm{min}$, and the absorbance of the metabolites was monitored at $254 \mathrm{~nm}$. The metabolic product was quantified by its ratio to $8-\mathrm{MOP}$.

\section{Results and Discussion}

\section{Heterologous Expression of N-Terminal-Modified CYP53A15} in E. coli Cells

In most cases, full-length forms of eukaryotic membranebound P450 genes heterologously express as inactive forms or not in E. coli cells and thus we focussed on the N-terminal modification of the P450 sequence, which provides an 
improvement strategy for the heterologous expression of membrane-bound P450 genes as described previously [15]. The Pro-Gly (PG)-rich site is conserved between the $\mathrm{N}$-terminal membrane-anchoring domain and the functional domain of membrane-bound P450 sequences [16]. We constructed plasmids for coexpression of P450, in which the $\mathrm{N}$-terminal membrane-anchoring sequence upstream of the PG-rich site was replaced with different $\mathrm{N}$-terminal amino acids of mammal P450 suitable for heterologous expression in E. coli cells, and human CPR genes. In fact, by using constructed plasmids, heterologous production of active human CYP2A4, CYP2C2, CYP2C29, CYP2C43, and CYP2D22 has successfully done [12]. In this study, to coexpress CYP53A15 and CPR in E. coli cells, the CYP53A15 cDNA without the N-terminal membrane-anchoring sequence (102 bp from start codon) was introduced into membranebound P450 expression plasmids (Fig. 1B). The PG site of CYP53A15 corresponding to $\mathrm{C}_{103} \mathrm{CGGCG}_{108}$ (Pro-Ala) was mutated to the SmaI recognition site (CCCGGG, Pro-Gly) necessary for introduction of CYP53A15 cDNA into the expression vectors (Fig. 1A). The membrane-bound P450 expression vectors used in this study (pCWRm1A2N, - rab2C3N, -r2C11N, -m2C29N, and -h2E1N) contained $\mathrm{N}$-terminal amino acid sequences of mouse CYP1A2 (MAL LLAVFLFCLVFWMVRASRTQVPKGLKNP), rabbit CYP2C3 (MAKKTSSKGKLP), rat CYP2C11 (MARQSFGRGKLP), mouse CYP2C29 (MARQSSGRGKLP), and human CYP2E1 (MARQVHSSWNLP), respectively, as partial N-terminal membrane-anchoring sequences from mammals (Fig. 1C).

E. coli JM109 cells were transformed with the resulting

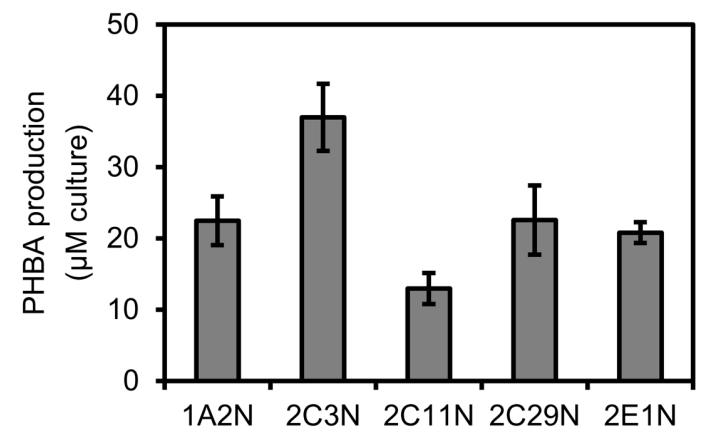

Fig. 2. PHBA production by E. coli JM109 cells transformed with plasmids encoding modified CYP53A15 with various Nterminal amino acids of mammalian P450 and human CPR: pCWRm1A2N-53A15, -rab2C3N-53A15, -r2C11N-53A15, m르29N-53A15, and -h르1N-53A15.

Underlining corresponds to the labels in the chart. CYP53A15 gene expression was induced in Terrific Broth medium at $25^{\circ} \mathrm{C}$ for $24 \mathrm{~h}$. Values are the mean $\pm \mathrm{SD}(n=3)$. plasmids. The E. coli cells carrying these plasmids were cultured and, after induction of CYP53A15 expression, the P450 content and PHBA productivity of the collected E. coli cells were measured. Although none of the transformed cells showed a characteristic peak at $450 \mathrm{~nm}$ in their COdifference spectra (Fig. S1), they all produced PHBA (Figs. 2 and S2). This finding suggests the production of a functional CYP53A15 enzyme. Among the tested transformants, PHBA production was the highest $(37 \pm 5 \mu \mathrm{M}$ culture) in E. coli cells transformed with pCWRrab2C3N53A15; thus, this transformant was used for further experiments. A previous study has shown that the combination of CYP53A15 and C. lunatus CPR1 produces PHBA, whereas CYP53A15 with C. lunatus CPR2 produces 3,4-dihydroxybenzoate [6]. In this study, we show that the combination of CYP53A15 and human CPR produces only PHBA from benzoate, as expected.

\section{Optimization of Culture Conditions for E. coli Cells Expressing CYP53A15}

First, we tested a range of induction temperatures for CYP53A15 using the recombinant E. coli JM109 cells transformed with pCWRrab2C3N-53A15. The CO-difference spectra of E. coli cells cultured at $15^{\circ} \mathrm{C}$ and $20^{\circ} \mathrm{C}$ showed obvious peaks at $450 \mathrm{~nm}$, but not those cultured at $25^{\circ} \mathrm{C}$ and $30^{\circ} \mathrm{C}$ (Figs. $3 \mathrm{~A}$ and S3). PHBA production was detected under all of the tested induction temperatures (Fig. 3B). As E. coli cells cultured at $20^{\circ} \mathrm{C}$ showed the highest $\mathrm{P} 450$ content (98 $\pm 9 \mathrm{nM}$ culture) and PHBA productivity (106 \pm $10 \mu \mathrm{M}$ culture), $20^{\circ} \mathrm{C}$ was used as the induction temperature in all subsequent experiments. Previous studies have used an induction temperature of $30^{\circ} \mathrm{C}$ for the expression of CYP53A15 in E. coli cells [6, 7]. We detected no P450 content and weak PHBA productivity $(5 \pm 1 \mu \mathrm{M}$ culture) in E. coli cells cultured at $30^{\circ} \mathrm{C}$ (Fig. 3), suggesting that the optimum conditions for our CYP53A15 expression system are different from those of systems reported previously. In the case of bioconversion from L-phenylalanine to phenylacetonitrile in E. coli cells coexpressing plant P450 CYP79A2 and aldoxime dehydratase, culture at low temperature $\left(16^{\circ} \mathrm{C}\right.$ and $\left.20^{\circ} \mathrm{C}\right)$ results in higher phenylacetonitrile production than that high temperature $\left(26^{\circ} \mathrm{C}, 30^{\circ} \mathrm{C}\right.$, and $\left.37^{\circ} \mathrm{C}\right)$ [17]. Heterologous production of the $\mathrm{P} 450$ enzyme (P450SMO) from Rhodococcus sp. ECU0066 in E. coli cells was also reported to be higher under low induction temperatures $\left(20^{\circ} \mathrm{C}\right.$ and $\left.25^{\circ} \mathrm{C}\right)$ than under high induction temperatures $\left(30^{\circ} \mathrm{C}\right.$ and $\left.37^{\circ} \mathrm{C}\right)$ [18]. Moreover, CYP53A15 would be unstable and rapidly inactivated under mesophilic conditions higher than $25^{\circ} \mathrm{C}$, which is also the case for other P450 enzymes, including 

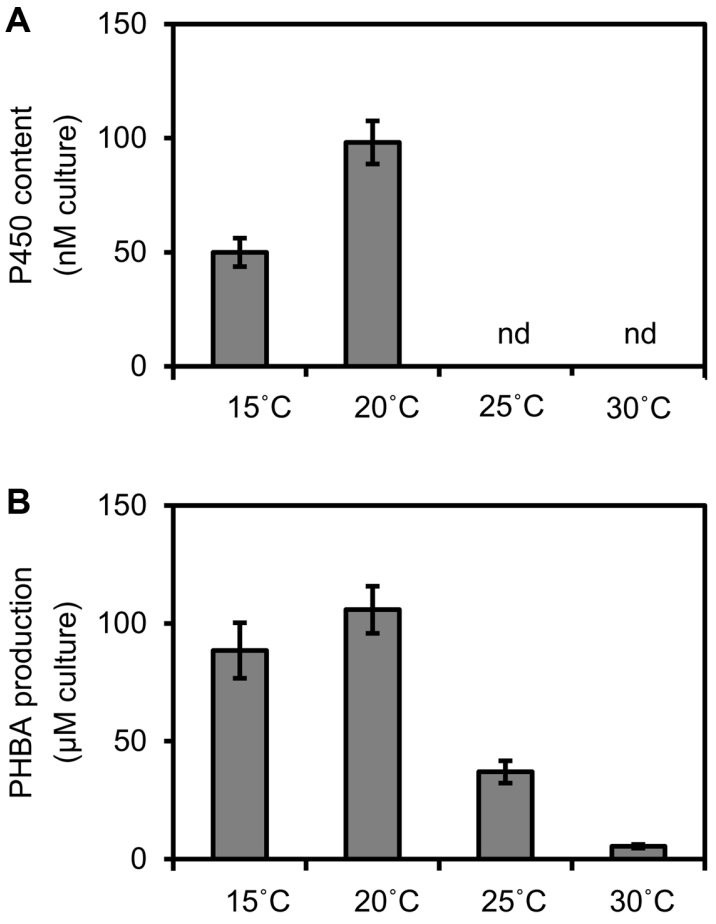

Fig. 3. Effect of induction temperature of the CYP53A15 in E. coli JM109 cells transformed with pCWRrab2C3N-53A15 on (A) P450 content and (B) PHBA production. CYP53A15 expression was induced in Terrific Broth medium at $15^{\circ} \mathrm{C}$, $20^{\circ} \mathrm{C}, 25^{\circ} \mathrm{C}$, and $30^{\circ} \mathrm{C}$ for $24 \mathrm{~h}$. Values are the mean $\pm \mathrm{SD}(n=3)$. nd, not detectable.

\section{CYP79A2 and P450SMO.}

Next, to further optimize CYP53A15 expression, we tested various E. coli host strains. By screening of an E. coli singlegene knockout collection (the Keio collection) on the basis of 7-ethoxycoumarin deethylase activity, E. coli mutants $(\Delta c p x A, \Delta g c v R$, and $\Delta g \ln L)$ with enhanced CYP154A1 activity but without obvious growth inhibition have been identified [19]. CpxA is a membrane-bound sensory histidine kinase that participates in a two-component regulatory system in E. coli [20]. The Cpx system is involved in the regulation of lactose analog uptake [21]. Disruption of the cpxA gene might alter lactose uptake, which was used as the inducer of heterologous gene expression. GcvR is a negative regulator of the glycine cleavage enzyme system [22]. GlnL is involved in the regulation of glutamine synthetase and nitrogen assimilation-related genes [23]. Disruption of the $g c v R$ or $g \ln L$ gene might alter cellular energy metabolism and redox balance in ways that are conducive to the CYP154A1 reaction in E. coli. Moreover, it has been shown that the E. coli $\triangle c p x A$ mutant enhances the activities of various $\mathrm{P} 450$ enzymes, such as compactin $6 \beta$ -
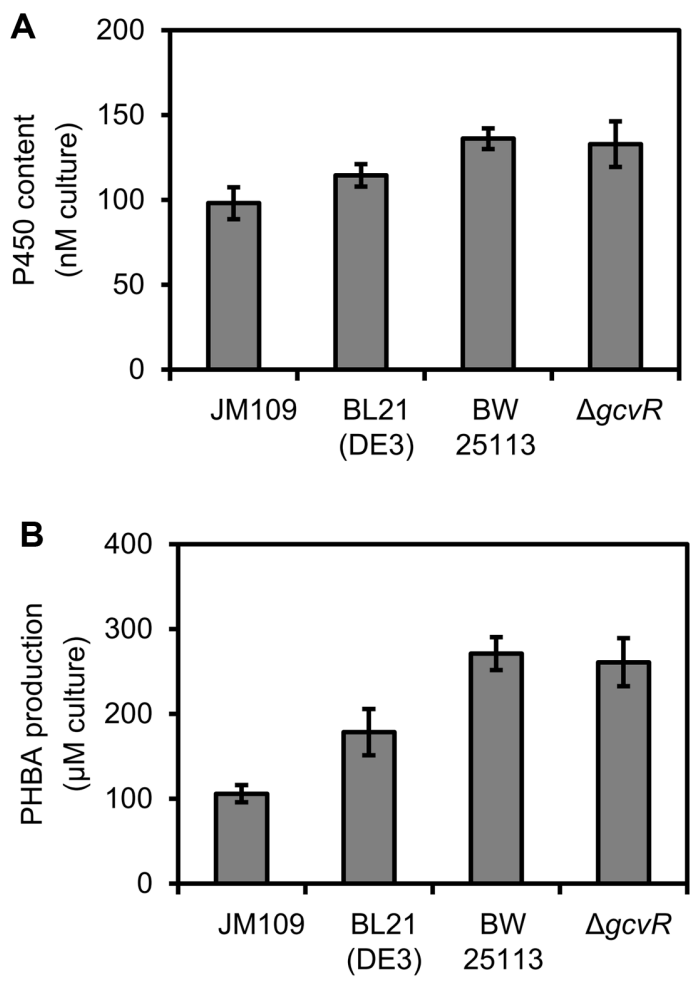

Fig. 4. Effect of host strain used for CYP53A15 expression on (A) P450 content and (B) PHBA production.

E. coli JM109, BL21(DE3), BW25113, and $\Delta g c v R$ cells were transformed with pCWRrab2C3N-53A15. CYP53A15 expression was induced in Terrific Broth medium at $20^{\circ} \mathrm{C}$ for $24 \mathrm{~h}$. Values are the mean $\pm \mathrm{SD}$ $(n=3)$.

hydroxylase, vitamin $\mathrm{D}_{3}$ hydroxylase, and an F87V mutant of CYP102A1 (BM3), as well as CYP154A1 [24]. In this study, general E. coli expression strains JM109 and BL21(DE3), the three single-gene knockout strains described above, and their parent strain (BW25113) were compared as expression hosts of CYP53A15. Each E. coli host was transformed with pCWRrab2C3N-53A15, and the P450 content and PHBA productivity of the cultured cells were measured. We found that the P450 contents of E. coli BW25113 and $\Delta g c v R$ were 1.4-times and the PHBA productivities 2.5-times those of E. coli JM109 cells (Fig. 4). These results suggest that the E.coli BW25113 and $\Delta g c v R$ strains are more suitable for PHBA production. The P450 contents and PHBA productivities of the other E. coli single-gene knockout strains, $\Delta c p x A$ and $\Delta g l n L$, were lower than those of E. coli JM109 (data not shown). Furthermore, we detected no significant difference in these variables between E. coli BW25113 and $\Delta g c v R$ and thus there was no effects on P450 activity by the single-gene knockouts. These findings might be due to the different redox partners, which were 

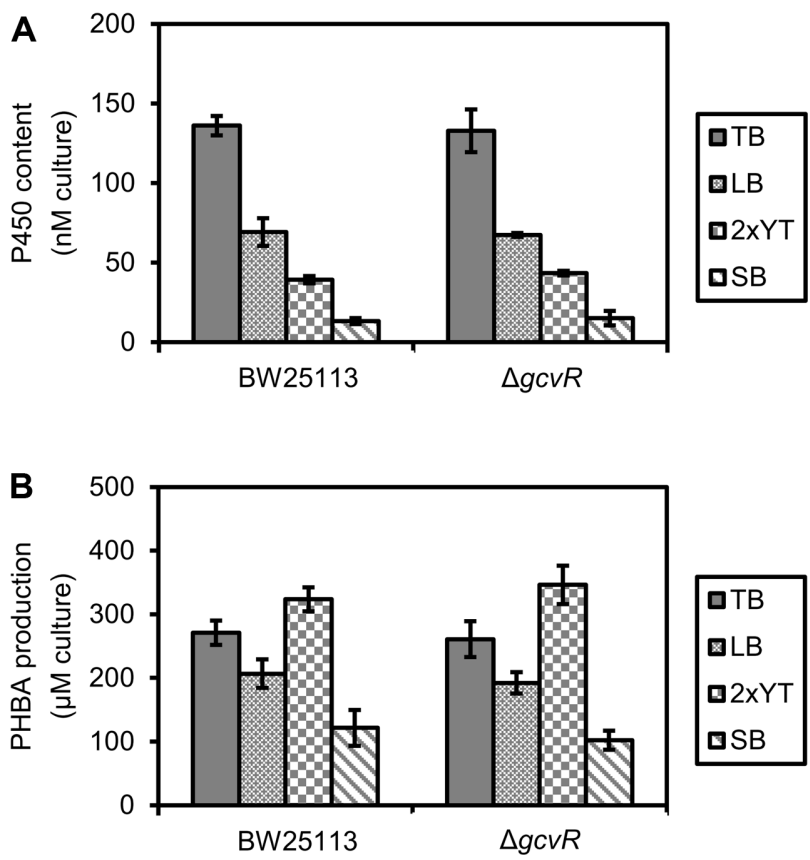

Fig. 5. Effect of culture medium used for CYP53A15 expression on (A) P450 content and (B) PHBA production in E. coli BW25113 and $\Delta g c v R$ cells transformed with pCWRrab2C3N-53A15. CYP53A15 expression was induced in Terrific Broth (TB), LB, 2×YT, and or Super Broth (SB) medium at $20^{\circ} \mathrm{C}$ for $24 \mathrm{~h}$. Values are the mean $\pm \mathrm{SD}(n=3)$.

putidaredoxin and putidaredoxin reductase, but not CPR, in the case of CYP154A1, for P450 under each experimental condition [19].

We also examined CYP53A15 expression in various growth media: the total nutrient content in the tested media decreased in the order of $\mathrm{SB}>\mathrm{TB}>2 \times \mathrm{YT}>\mathrm{LB}$. In E. coli BW25113 and $\Delta g c v R$ cells, the P450 contents were the highest in TB medium, whereas PHBA productivity was the highest in $2 \times Y \mathrm{~T}$ medium (Fig. 5). Cultured in $2 \times \mathrm{YT}$, $\Delta g c v R$ cells produced slightly more P450 (346 $\pm 30 \mu \mathrm{M}$ culture) than did BW25113 cells $(323 \pm 19 \mu \mathrm{M}$ culture). These results might be due to cells cultured in TB medium expressing an excess of the CYP53A15 enzyme, some of which is not enzymatically functional, and cells cultured in $2 \times$ YT medium (a better reaction condition for the CYP53A15) producing more PHBA than cells cultured in TB medium. In E. coli cells expressing CYP1A1, activity was lower for culture in TB medium than in nutrient-poor M9 mineral medium supplemented with glucose as a carbon source [25]. In E. coli cells expressing the P450 enzyme isoflavonone synthase, the conversion rate of cells cultured in TB medium was lower than that in cells cultured in the nutrient-poor
LB medium [26]. Thus, a low-nutrient medium (e.g., $2 \times Y \mathrm{~T}$, M9 with glucose, and LB) tends to be more suitable for P450-mediated whole-cell conversion than the more nutrientrich TB medium. In contrast, culture in TB medium results in high biomass yield. However, there was no significant difference between the final $\mathrm{OD}_{600}$ values of E. coli $\Delta g c v R$ cells cultured in TB $(4.4 \pm 0.1)$ and $2 \times Y$ T media $(4.2 \pm 0.1)$. In this study, we determined that $2 \times Y \mathrm{~T}$ medium was suitable for CYP53A15 expression in E. coli on the basis of both PHBA productivity and biomass yield.

\section{Optimization of the Reaction Conditions for PHBA Production}

First, we identified the optimal temperature: PHBA productivity at $25^{\circ} \mathrm{C}$ was 1.2 -times that at the $30^{\circ} \mathrm{C}$ used in the above experiments (Fig. 6A). This $25^{\circ} \mathrm{C}$ temperature was similar to the optimal growth temperature of C. lunatus [6] and was used for all subsequent experiments.

To maximize cost-effectiveness, we estimated the conversion ratio from benzoate to PHBA under various substrate concentrations. Under the reaction conditions used, most of the benzoate was not reacted when using a substrate concentration of $2 \mathrm{mM}$, whereas the benzoate was totally converted to PHBA when a substrate concentration of $0.1 \mathrm{mM}$ was used. The conversion ratios at the 0.2 and $0.5 \mathrm{mM}$ substrate concentrations were $58 \pm 3 \%$ and $27 \pm 1 \%$, respectively (Fig. 6B). We aimed to completely convert 0.2 and $0.5 \mathrm{mM}$ benzoate by further optimization of the reaction conditions.

Next, we examined the effects of reaction time. As expected, prolonging the reaction time increased the conversion ratio of benzoate, perhaps because the reaction progressed gradually owing to the NADPH regeneration cycle acting as a rate-limiting step in the E. coli cells [5]. When the reaction time was prolonged by $48 \mathrm{~h}, 0.2 \mathrm{mM}$ benzoate was completely converted, whereas the conversion ratio at the $0.5 \mathrm{mM}$ substrate concentration was increased to $45 \pm 1 \%$ (Fig. 6C).

We hypothesized that the low conversion ratio at the substrate concentration of $0.5 \mathrm{mM}$ was caused by limited NADPH regeneration. Therefore, we attempted to improve the conversion ratio by increasing the $E$. coli cell concentration in the reaction solution. By this approach, the conversion ratio reached $90 \pm 2 \%$ at $\mathrm{OD}_{600}=2.5$ (Fig. $6 \mathrm{D}$ ), corresponding to double the concentration of $E$. coli cells than that used in the above experiments. The PHBA productivity under the same conditions was $450 \pm 8 \mu \mathrm{M}$ culture, which is 12 times that before optimization (under the initial reaction conditions using E.coli JM109 cells transformed with 


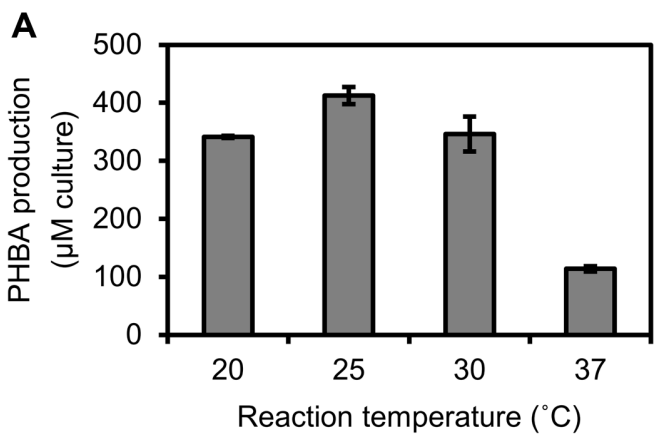

C

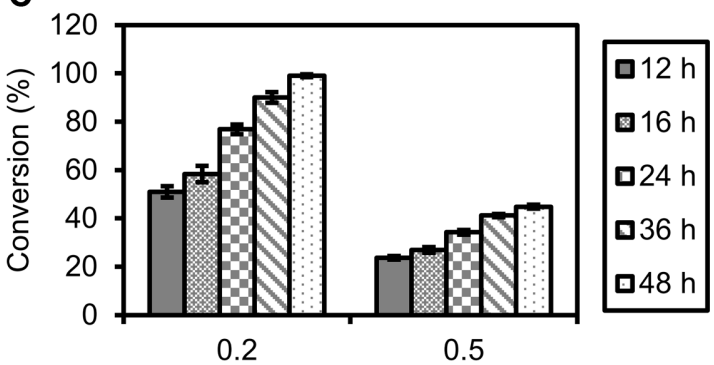

Substrate concentration $(\mathrm{mM})$

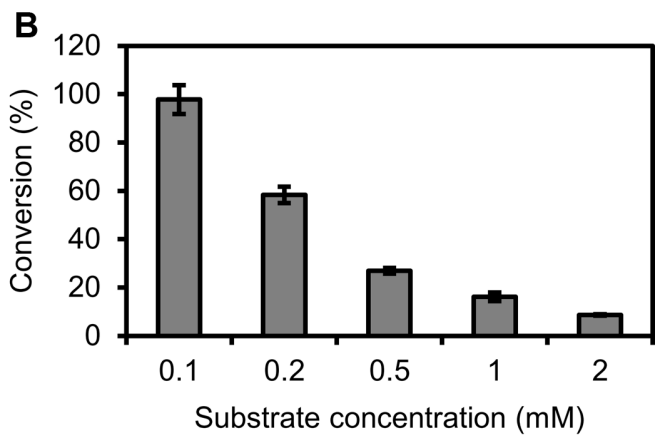

D

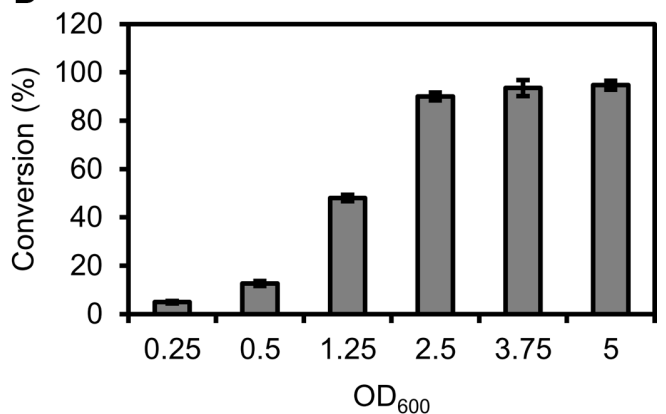

Fig. 6. Optimization of the benzoate $p$-hydroxylase reaction conditions for PHBA production (A) and the conversion ratio of benzoate (B-D) in E. coli $\Delta g c v R$ cells transformed with pCWRrab2C3N-53A15.

The reaction was performed in the presence of $(\mathbf{A}) 2 \mathrm{mM}$ benzoate at $20^{\circ} \mathrm{C}, 25^{\circ} \mathrm{C}, 30^{\circ} \mathrm{C}$, and $37^{\circ} \mathrm{C}$ for $16 \mathrm{~h} ;(\mathbf{B}) 0.1,0.2,0.5,1$, and $2 \mathrm{mM}$ benzoate at $25^{\circ} \mathrm{C}$ for $16 \mathrm{~h}$; (C) 0.2 and $0.5 \mathrm{mM}$ benzoate at $25^{\circ} \mathrm{C}$ for $12,16,24,36$, and $48 \mathrm{~h}$; and (D) $0.5 \mathrm{mM}$ benzoate at $25^{\circ} \mathrm{C}$ for $48 \mathrm{~h}$. After adding E. coli suspension $(10,20,50,100,150$, or $200 \mu \mathrm{l})$ to $1 \mathrm{ml}$ of the reaction mixture, the $\mathrm{OD}_{600}$ values of the reaction mixture were $0.25,0.5,1.25,2.5,3.75$, and 5 , respectively. Values are the mean $\pm \mathrm{SD}(n=3)$.

pCWRrab2C3N-53A15) (Fig. 2). In a previous study, in yeast cells coexpressing CYP53A19 and CPR from Fusarium oxysporum and glucose dehydrogenase from Bacillus subtilis, which was introduced to enhance NADPH regeneration, only $61 \%$ of $0.5 \mathrm{mM}$ benzoate was converted to PHBA, despite using a high yeast cell concentration $(O D=200)$ [11]. Thus, our E. coli bioconversion system is more efficient at producing PHBA than the previously described yeast system.

Here, we were successful in the $p$-specific hydroxylation of benzoate by using a CYP53A15 and human CPR combination. As described above, CYP53A15 produces alternative reaction products depending on its combination with CPR [6]. As reaction products, our E. coli bioconversion system method does not produce $o$ - or $m$-hydroxybenzoate, or dihydroxybenzoate. Therefore, the CYP53A15 and human CPR used here are suitable for PHBA production. Moreover, we propose that PHBA productivity could be further improved by focusing on the regeneration of NADPH (electron donor) and the electron transfer from CPR to the CYP53A15 enzyme. The NADPH regeneration cycle is a rate-limiting step in whole-cell catalysis; coexpression of CYP53A19, CPR, and glucose dehydrogenase, which simultaneously oxidize glucose to glucolactone and produce $\mathrm{NADPH}$, has been shown to enhance NADPH regeneration and benzoate $p$-hydroxylation activity in yeast cells [11]. Moreover, the coexpression of glucose dehydrogenase markedly increased the conversion from indole to indigo in E. coli cells expressing a mutant BM3 enzyme [27, 28]. In the $\mathrm{P} 450$ reactions, the efficiency of electron transfer from CPR to P450 is also important. For this reason, previous studies have focused on the construction of a chimeric P450-CPR enzyme, with the aim of mimicking BM3, which is a fusion enzyme containing P450 and CPR domains: in the presence of substrate, the NADPH oxidation rate is markedly higher for a chimeric enzyme of human CYP3A4, and the CPR domain of BM3 is increased compared with separately prepared CYP3A4 and human CPR [29]. Thus, improvement of the $\mathrm{P} 450$ reaction environment by enhancing the NADPH regeneration cycle and fusion of CYP53A15 with CPR would likely further increase PHBA productivity. 
In summary, we have constructed a bioconversion to PHBA system in E. coli cells coexpressing CYP53A15 and human $C P R$. We then optimized the cultivation conditions (induction temperature, E. coli hosts, and medium) and benzoate $p$-hydroxylase reaction conditions (reaction temperature, substrate concentration, reaction time, and E. coli cell concentration). As a result, we increased PHBA productivity by a factor of 12 compared with the initial cultivation and reaction conditions, almost completely converting $0.5 \mathrm{mM}$ of benzoate to PHBA. These optimization methods, especially in use of E. coli expression plasmids of membrane-bound P450 constructed originally, would be applicable to the synthesis of other chemical materials and the heterologous expression of other P450 species, and be significant for $\mathrm{P} 450$ engineering in the field of microbial biotechnology.

\section{Acknowledgments}

This work was supported by a Japan Society for the Promotion of Science Grant-in-Aid for Scientific Research (KAKENHI, Grant JP15K12354) and by funds provided by Innovative BioProduction Kobe (Special Coordination Funds for Promoting Science and Technology; Creation of Innovation Centers for Advanced Interdisciplinary Research Areas) administered by the Japanese Ministry of Education, Culture, Sports, Science, and Technology. This work was in part carried out by the joint research program of Biosignal Research Center, Kobe University. We thank NBRP-E. coli at NIG for providing us with the E. coli single-gene knockout strains.

\section{References}

1. Padias AB, Hall HK. 2011. Mechanism studies of LCP synthesis. Polymers 3: 833-845.

2. Nelson DR. 1999. Cytochrome P450 and the individuality of species. Arch. Biochem. Biophys. 369: 1-10.

3. Omura T, Takesue S. 1970. New method for simultaneous purification of cytochrome $b_{5}$ and NADPH-cytochrome $c$ reductase from rat liver microsomes. J. Biochem. 67: 249-257.

4. Bernhardt R. 2006. Cytochromes P450 as versatile biocatalysts. J. Biotechnol. 124: 128-145.

5. O'Reilly E, Köhler V, Flitsch SL, Turner NJ. 2011. Cytochromes P450 as useful biocatalysts: addressing the limitations. Chem. Commun. (Camb.) 47: 2490-2501.

6. Lah L, Podobnik B, Novak M, Korošec B, Berne S, Vogelsang $\mathrm{M}$, et al. 2011. The versatility of the fungal cytochrome P450 monooxygenase system is instrumental in xenobiotic detoxification. Mol. Microbiol. 81: 1374-1389.
7. Podobnik B, Stojan J, Lah L, Krasevec N, Seliskar M, Rizner TL, et al. 2008. CYP53A15 of Cochliobolus lunatus, a target for natural antifungal compounds. J. Med. Chem. 51: 3480-3486.

8. Harwood CS, Parales RE. 1996. The $\beta$-ketoadipate pathway and the biology of self-identity. Annu. Rev. Microbiol. 50: 553-590.

9. Jawallapersand P, Mashele SS, Kovačič L, Stojan J, Komel R, Pakala SB, et al. 2014. Cytochrome P450 monooxygenase CYP53 family in fungi: comparative structural and evolutionary analysis and its role as a common alternative anti-fungal drug target. PLoS One 9: e107209.

10. Noda S, Kitazono E, Tanaka T, Ogino C, Kondo A. 2012. Benzoic acid fermentation from starch and cellulose via a plant-like $\beta$-oxidation pathway in Streptomyces maritimus. Microb. Cell Fact. 11: 49.

11. Jeon H, Durairaj P, Lee D, Ahsan MM, Yun H. 2016. Improved NADPH regeneration for fungal cytochrome P450 monooxygenase by co-expressing bacterial glucose dehydrogenase in resting-cell biotransformation of recombinant yeast. J. Microbiol. Biotechnol. 26: 2076-2086.

12. Goto T, Moriuchi H, Fu X, Ikegawa T, Matsubara T, Chang G, et al. 2010. The effects of single nucleotide polymorphisms in CYP2A13 on metabolism of 5-methoxypsoralen. Drug Metab. Dispos. 38: 2110-2116.

13. Omura T, Sato R. 1964. The carbon monoxide-binding pigment of liver microsomes. I. Evidence for its hemoprotein nature. J. Biol. Chem. 239: 2370-2378.

14. Yun $\mathrm{CH}$, Yim SK, Kim DH, Ahn T. 2006. Functional expression of human cytochrome P450 enzymes in Escherichia coli. Curr. Drug Metab. 7: 411-429.

15. Yamazaki S, Sato K, Suhara K, Sakaguchi M, Mihara K, Omura T. 1993. Importance of the proline-rich region following signal-anchor sequence in the formation of correct conformation of microsomal cytochrome P-450s. J. Biochem. 114: 652-657.

16. Uno T, Nakao A, Masuda S, Taniguchi Y, Kanamaru K, Yamagata $\mathrm{H}$, et al. 2006. Modification of small molecules by using cytochrome P450 expressed in Escherichia coli. J. Ind. Microbiol. Biotechnol. 33: 1043-1050.

17. Miki Y, Asano Y. 2014. Biosynthetic pathway for the cyanide-free production of phenylacetonitrile in Escherichia coli by utilizing plant cytochrome P450 79A2 and bacterial aldoxime dehydratase. Appl. Environ. Microbiol. 80: 6828-6836.

18. Zhang JD, Li AT, Xu JH. 2010. Improved expression of recombinant cytochrome P450 monooxygenase in Escherichia coli for asymmetric oxidation of sulfides. Bioprocess Biosyst. Eng. 33: 1043-1049.

19. Zhou Y, Minami T, Honda K, Omasa T, Ohtake H. 2010. Systematic screening of Escherichia coli single-gene knockout mutants for improving recombinant whole-cell biocatalysts. Appl. Microbiol. Biotechnol. 87: 647-655.

20. De Wulf P, McGuire AM, Liu X, Lin EC. 2002. Genome-wide profiling of promoter recognition by the two-component 
response regulator CpxR-P in Escherichia coli. J. Biol. Chem. 277: 26652-26661.

21. Plate CA, Seely SA, Laffler TG. 1986. Evidence for a protonmotive force related regulatory system in Escherichia coli and its effects on lactose transport. Biochemistry 25: 6127-6132.

22. Ghrist AC, Stauffer GV. 1995. Characterization of the Escherichia coli gcoR gene encoding a negative regulator of gcv expression. J. Bacteriol. 177: 4980-4984.

23. Ginsburg A, Stadtman ER. 1973. Regulation of glutamine synthetase in Escherichia coli, pp. 9-43. In Prusiner S, Stadtman ER (eds.). The Enzymes of Glutamine Metabolism. Academic Press, New York.

24. Zhou Y, Minami T, Honda K, Omasa T, Ohtake H. 2010. Enhancement of recombinant enzyme activity in cpxA-deficient mutant of Escherichia coli. J. Biosci. Bioeng. 110: 403-407.

25. Cornelissen S, Julsing MK, Schmid A, Bühler B. 2012. Comparison of microbial hosts and expression systems for mammalian CYP1A1 catalysis. J. Ind. Microbiol. Biotechnol.
39: $275-287$.

26. Kim DH, Kim BG, Jung NR, Ahn JH. 2009. Production of genistein from naringenin using Escherichia coli containing isoflavone synthase-cytochrome P450 reductase fusion protein. J. Microbiol. Biotechnol. 19: 1612-1616.

27. Li QS, Schwaneberg U, Fische P, Schmi RD. 2000. Directed evolution of the fatty-acid hydroxylase P450 BM-3 into an indole-hydroxylating catalyst. Chem. Eur. J. 6: 1531-1536.

28. Lu Y, Mei L. 2007. Co-expression of P450 BM3 and glucose dehydrogenase by recombinant Escherichia coli and its application in an NADPH-dependent indigo production system. J. Ind. Microbiol. Biotechnol. 34: 247-253.

29. Degregorio D, D'Avino S, Castrignanò S, Di Nardo G, Sadeghi SJ, Catucci G, et al. 2017. Human cytochrome P450 $3 \mathrm{~A} 4$ as a biocatalyst: effects of the engineered linker in modulation of coupling efficiency in 3A4-BMR chimeras. Front. Pharmacol. 8: 121. 